DOI: http://dx.doi.org/10.23925/2176-2767.2018v63p205-239

Data de submissão: 06/07/2018Ｄata aprovação: 20/10/2018

\title{
ARTIGO
}

\section{MAIO DE 1968 NA UNIVERSIDADE FEDERAL DO PARANÁ (UFPR)}

\section{MAY 1968 AT FEDERAL UNIVERSITY OF PARANÁ (UFPR)}

\author{
NÉVIO DE CAMPOS* \\ ELIEZER FELIX DE SOUZA**
}

\begin{abstract}
RESUMO
Este artigo objetiva discutir o Maio de 1968 na Universidade Federal do Paraná (UFPR), privilegiando um olhar sobre o movimento universitário estudantil. Esse acontecimento é tomado como resultado de eventos anteriores e como abertura de possíveis, isto é, o Maio de 68 é explicado na correlação com os acontecimentos antecedentes e com os horizontes de expectativa que mobilizavam aqueles jovens estudantes. Apoia-se nas fontes arquivadas pela Delegacia de Ordem Política e Social (DOPS) que serviram para fichar e processar as lideranças estudantis e nas atas do Conselho Universitário da UFPR, na tentativa de mostrar as ações dos estudantes e as formas repressivas postas em prática pelas autoridades universitárias e policiais.
\end{abstract}

PALAVRAS-CHAVE: Maio de 1968; Movimento Estudantil; Universidade Federal do Paraná.

ABSTRACT:

The aim of this article is to discuss the month of May of 1968 at the Federal University of Paraná (UFPR), highlighting the university student movement. This fact is the result of previous events as well as initiating possible future ones, that is, May 1968 is explained in correlation with preceding events and with expectations which mobilized those young students. This article is based on sources filed by the Police for Political and Social Order (DOPS) which served to file and sue student leaders and the minutes of the Council of the Federal University of Paraná, in an attempt to show student actions and repressive ways put in practice by university and police authorities.

KEYWORDS: May 1968; Student Movement; Federal University of Paraná. 


\section{Introdução}

Os movimentos associados a Maio de 1968 no Brasil ocorreram no contexto do regime militar, em vigor desde 1964. Se o movimento de 1968 é conhecido pelo estopim de mobilizações de diferentes grupos, em diversos lugares do mundo, é possível dizer que tais ações estavam relacionadas à organização social, anteriormente estabelecida, bem como a demandas gerais e específicas de cada cidade e instituição.

Maio de 1968 é tomado como um acontecimento crítico, para usar a acepção de Bourdieu. Assim sendo:

A atenção imediata ao imediato que, mergulhado no acontecimento e nas impressões que ele suscita, isola o momento crítico, assim constituído como totalidade limitando em si mesma sua explicação, introduz desse modo uma filosofia da história: ela leva a pressupor que há na história momentos privilegiados, de qualquer forma mais históricos que os outros. ${ }^{2}$

Bourdieu observa que "a intenção científica ao contrário visa recolocar o acontecimento extraordinário na série dos acontecimentos ordinários, no interior dos quais ele se explica". Além disso, acrescentaríamos aquilo que François Dosse chama de abertura de possíveis, ao dialogar com Gilles Deleuze e Félix Guattari. Nesse sentido duplo, acontecimento é entendido "[...] como resultado e como começo, como desfecho e como abertura de possíveis". ${ }^{4}$ Mais adiante, este historiador reafirma essa ideia ao dizer que "o acontecimento nos revela subitamente algo escondido no passado que vem à tona para mudar o trajeto. Logo, ele seria ao mesmo tempo que começo, a conclusão desse começo obscuro até o rompimento temporal que ele encarna". ${ }^{5}$ 
No contexto internacional, conforme registra Michel Thiollent, em particular "em Paris, as lutas universitárias de 1968 ocorreram durante um período de tempo no qual interferiam vários outros eventos históricos. A oposição à guerra americana no Vietnã mobilizava a juventude tanto nos EUA quanto na Europa". ${ }^{6}$ Além disso, observa este autor, "a revolta negroamericana, a luta armada na América Latina e na África, a Revolução Cultural na China (1966-1969) contribuíam para o clima de revolucionarização da juventude e do mundo universitário”. ${ }^{7}$ Ou seja, é importante assinalar que "as lutas que se manifestaram na universidade estão inseridas no contexto global da sociedade".

O Maio de 1968 no Brasil é objeto de muita produção acadêmica, como já indicamos na primeira nota de fim página. No contexto brasileiro, as movimentações foram intensas e diversas, conforme atestam Ricardo Antunes e Marcelo Ridenti:

Em 1968 presenciamos a era das múltiplas explosões e revoltas: operárias, estudantis, feministas, dos negros, dos movimentos ambientalistas, dos homossexuais, dentre tantas outras formas de levante e descontentamento social e político, naqueles anos que selavam o "fim dos anos dourados".?

Nesse ambiente inserem-se as mobilizações estudantis que se somaram a outros movimentos sociais e pintaram o que ficou conhecido como Maio de 1968. Sobre esse momento, destaca Marcelo Ridenti que, "no Brasil, acima da influência dos fatores internacionais e da identidade com movimentos contestadores de outros países, 1968 teve especificidades locais determinantes. O movimento estudantil daquele ano, por exemplo, nasceu de uma dinâmica de luta própria, anterior a maio de $1968 \% .{ }^{10}$ Ao mesmo tempo, conforme Ricardo Antunes e Marcelo Ridenti: 
As greves metalúrgicas de Osasco (região industrial na grande São Paulo, desencadeada em julho) e as greves de Contagem (região industrial na grande Belo Horizonte, Minas Gerais, deflagradas em abril e outubro do mesmo ano de 1968), encontram suas origens e raízes muito marcadas pela particularidade brasileira, em plena luta contra a ditadura militar. ${ }^{11}$

Reconhecer as peculiaridades do Maio de 1968 no Brasil não implica eclipsar as similitudes desse movimento que atingiu diferentes partes do planeta, como observam Antunes e Ridenti:

Em diferentes medidas, havia similaridade em condições como a industrialização avançada, a crescente urbanização e consolidação de modos de vida e cultura das metrópoles, a massificação dada pela indústria cultural, o aumento do proletariado e das classes médias assalariadas, a importância dos jovens na composição etária da população, o acesso crescente ao ensino superior, além da incapacidade do poder constituído para representar sociedades que se renovavam. ${ }^{12}$

A partir do exposto, indaga-se: como estavam dadas as movimentações do Maio de 1968 na capital do Paraná? Já objeto de estudo, foi retratado nos capítulos de livro 1968: ano da derrubada do ensino pago no Parana,$^{13}$ e Contextos e traumas do maio de 1968 na UFPR. ${ }^{14}$ O primeiro retrata o episódio que resultou no cancelamento do pagamento de anuidades, no ano de 1968. O segundo cobre os confrontos dos primeiros meses de 1968 que culminaram nos episódios de maio. Além desses estudos, destacamos as produções de Silvana Lazzarotto Schmitt e Alexandre Felipe Fiuza, ${ }^{15}$ Andréia Zaparte, ${ }^{16}$ Amilton Costa, ${ }^{17}$ Jaime Mansan ${ }^{18}$ e José Szwako. ${ }^{19} \mathrm{Na}$ esteira das reflexões que tratam dos 50 anos do Maio de 1968 inscreve-se este artigo, cujo recorte privilegia um olhar sobre a organização estudantil na Universidade Federal 
do Paraná (UFPR).

\section{Da pauta política do Hugo Simas (1959) à tomada da UPE (1967)}

A organização estudantil paranaense não estava restrita apenas às pautas específicas. Ao menos parte dos estudantes associava suas mobilizações a plataformas políticas mais gerais. Essa assertiva pode ser observada em carta de 24 de abril de 1959, assinada por Dante Leonelli e endereçada ao líder do Movimento Unificador dos Trabalhadores (MUT):

Tendo os dirigentes do Centro Acadêmico Hugo Simas, da Faculdade de Direito da Universidade do Paraná, manifestado o mais vivo desejo de convidar LUIS CARLOS PRESTES para realizar uma conferência sobre assuntos políticos, nesta capital, sob o patrocínio da referida entidade estudantil, consulto, pela presente, o amigo, sobre a conveniência e oportunidade de ser dirigido a Prestes o aludido convite, bem como o endereço que pode ou deve ser utilizado pelos estudantes, para o envio direto do mesmo. 20

Essa carta foi apreendida pela DOPs e integra o Inquérito Policial Militar com data de 06 de outubro de 1965. A ideia da citação de parte do conteúdo da referida carta é evidenciar que aspectos políticos estavam na pauta estudantil do Paraná, em específico do Centro Acadêmico do Curso de Direito. Essa tendência do grupo paranaense pode ser aproximada do movimento da própria organização estudantil brasileira, pois, de acordo com Carla Sant'Ana Brandão Costa, “apesar da constante ascensão e queda da ala progressista da UNE durante a década de 1950, finda, na segunda metade dessa década, o período direitista na UNE e ocorre a reconquista, pela ala progressista, do controle da entidade". ${ }^{21}$ Além disso, observa 
Brandão Costa, “outra característica presente no Movimento Estudantil durante o final da década de 1950 foi a aliança dos estudantes com a classe trabalhadora a fim de viabilizar uma nova ordem social". ${ }^{22}$

Nesse contexto pode ser interpretado o movimento de estudantes paranaenses que se associava às pautas de natureza política mais geral. Em 4 de julho de 1957, conforme Andréia Zaparte, há nos relatórios da Seção de Ordem Política e Social do Estado do Paraná, referência do afastamento de Nobutero Matsuda (presidente entre 1957/1958) da União Paranaense dos Estudantes (UPE), ${ }^{23}$ por estar envolvido com ideias comunistas e com práticas subversivas. Nesse relatório, segundo Zaparte, a polícia sustentava que "a diretoria da U.P.E é totalmente esquerdista, com exceção do $1^{\circ}$ VicePresidente e os membros da Secretaria". ${ }^{24}$

Conforme Mateus Lima, “em 1961, o grupo mais à esquerda da JUC chegou à presidência da UNE, com a vitória da Aldo Arantes”, ${ }^{25}$ já atuando de modo efetivo no I Seminário Nacional de Reforma Universitária, realizado entre 20 e 27 de maio de 1961, na cidade de Salvador. Conforme Cunha, "durante o seminário foram realizados painéis sobre a questão da reforma universitária, para os quais foram convidados professores e administradores educacionais". ${ }^{26}$ Logo após o Seminário de Salvador, foi aprovada a nova legislação da educação com elementos que divergiam do que os estudantes esperavam.

Entre 17 e 24 de março de 1962 os estudantes realizaram o II Seminário Nacional de Reforma Universitária, em Curitiba. Na Carta do Paraná, os estudantes reiteraram suas críticas ao imperialismo e a subserviência brasileira. A defesa da educação pública e gratuita foi a grande tônica do Seminário de Curitiba, além da demanda para ampliar a 
participação estudantil nos conselhos. Tão logo este Seminário foi concluído, "a UNE empenhou-se na propaganda da reforma universitária". ${ }^{27}$ Essa discussão visava forçar o poder público a regulamentar a participação de $1 / 3$ dos estudantes nos conselhos deliberativos das instituições universitárias. De acordo com Cunha, a mobilização da UNE “'[...] foi fundamental para a greve do 'um terço’, já que a questão da representação estudantil era um dos pontos mais importantes das reivindicações da Carta do Paraná". ${ }^{28}$

Segundo Mateus Lima, “as universidades tinham até o dia 27 de junho de 1962 para adequarem os seus estatutos à nova lei. A partir do Seminário de Curitiba, os centros, diretórios e federações acadêmicas pressionaram as reitorias, sem sucesso, para incluir as reivindicações estudantis". ${ }^{29}$ Diante disso, "em maio, o Conselho da UNE reuniu-se no Maranhão e decidiu dar o prazo até $1^{\circ}$ de junho para que os estatutos contemplassem a participação estudantil na proporção de 1/3. Como não ocorreu, a UNE decretou greve, decisão ratificada pelas uniões estaduais". ${ }^{30}$ No Paraná, sob a coordenação da UPE, os estudantes aderiram à greve do 1/3. “A UPE decreta greve geral do movimento estudantil, reivindicando a participação nos CTAs (Conselhos Técnicos Administrativos), Congregações e Conselhos Departamentais das Universidades". ${ }^{31}$

Essa mobilização da UNE, seguida pela UPE na greve do 1/3 mostra a defesa de pautas estudantis. No entanto, os estudantes, também, defendiam pautas mais gerais, como articulação da luta estudantil à organização dos movimentos dos trabalhadores. Observa-se, de acordo com análise de Zaparte, a defesa das reformas de base, entre elas, a universitária. Conforme essa autora, “a União Paranaense dos Estudantes 
procurou fortalecer a aliança com os trabalhadores, recorrendo à sua colaboração na luta pela educação e se mostrando disposta a prestar suas contribuições nas lutas dos trabalhadores". ${ }^{32}$

Com o regime militar, a organização estudantil passou a sofrer forte combate. $\mathrm{Na}$ avaliação de Jordana de Souza Santos, a reverberação da Lei Suplicy e da repressão como um todo fez com que o movimento estudantil intensificasse sua luta contra o Ministro da Educação e, sobretudo, “[...] em 1966, ano em que foi decretado pela UNE em 22 de setembro o Dia Nacional de Luta contra a Ditadura". 33 Para Antônio Maria Freitas Brito, “a Lei Suplicy Lacerda despertou reações contrárias no meio estudantil contribuindo, paradoxalmente, para a rearticulação do ME em oposição ao Governo". ${ }^{4}$ Segundo o autor, as primeiras críticas à medida partiram de entidades que "[...] haviam escapado ao fechamento e à repressão porque haviam se colocado, tacitamente, a favor da intervenção militar. Trata-se [...] das UEEs de Pernambuco, Minas Gerais e Paraná [...] e da União Metropolitana dos Estudantes (UME) do Rio de Janeiro". ${ }^{35}$

A observação de Freitas Brito pode ser identificada no Paraná, pois, a partir de 1965, a UPE passou a apoiar o governo militar e a combater os chamados esquerdistas do movimento estudantil. No dia 26 de setembro, Osvaldo Cesar Ceccon (vice-presidente da UPE) enviou ofício às autoridades pedindo segurança e informando a natureza do evento a ser realizado no Auditório da Biblioteca Pública do Paraná: “o Ciclo versará sobre temas anticomunistas, subordinando-se ao Título: 'O Imperialismo Mundial Comunista, seus recursos e suas dificuldades para conquista do Mundo', e será prelecionado por Professores e Personalidades de São Paulo". 36 
O grupo que estava à frente da UPE era classificado nos relatórios da DOPs de democratas ardorosos, defensores do regime militar. Na outra ponta dessa disputa estavam os esquerdistas ardorosos, classificados de subversivos e inimigos da nação. No jornal Correio do Paraná de 12 de dezembro de 1965 constava a seguinte matéria:

A União Paranaense dos Estudantes não vinha endossar nenhum movimento de repúdio ao Ministro Suplicy, que ameaça fechar todas as entidades estudantis que não obedecerem a lei 4. 464" declarou ao Correio o estudante Ardisson Nain Akel, presidente do Conselho de Representantes do órgão. Acentuou que "sendo entidade civil e não havendo provas de que possa afetar a segurança nacional, a UPE não pode ser fechada" - assinalando que há maior preocupação por parte de sua diretoria nesse sentido. Se em outros Estados entidades congêneres estão manifestando seu desagrado a Lei Suplicy, o mesmo não acontece no Paraná. A UPE goza de situação privilegiada junto a classe estudantil nacional dada sua [sic] conduta em não permitir infiltração comunista em seus quadros, como anteriormente era comum" - disse o acadêmico. Frisou ainda, que a UPE continua liderando o movimento estudantil no Paraná que em virtude da linha nacionalista adotada, como também pelo fato do Diretório Estadual dos Estudantes não ter condições de funcionamento até agora. ${ }^{37}$

No início de 1966, conforme Zaparte, “a UPE mantinha seus privilégios junto às autoridades políticas e continuava realizando suas atividades normalmente, pois, com a forma de atuação de seus dirigentes, naquele momento, não representava uma ameaça ao poder constituído". ${ }^{38}$ No entanto, ainda naquele ano, as forças da esquerda ganharam espaço na UPE, em particular com aprovação de um relatório durante o $22^{\circ}$ Congresso, realizado em Curitiba. No referido relatório, entre tantas 
questões, foi aprovada uma crítica a então diretoria da UPE. Apesar disso, conforme destaca Zaparte, o grupo da situação da UPE venceu novamente a eleição. Esse grupo assim foi descrito pelas autoridades da DOPs Paraná:

Não há dúvida que a que nos inspira maior confiança é a chapa da Situação. Seu candidato é o atual VicePresidente de uma gestão sintonizada com os ideais revolucionários de 31 de Março. Os membros desta chapa são todos democratas autênticos, ardorosos e prometem uma boa gestão. ${ }^{39}$

Naquele momento, as resistências saiam de alguns diretórios acadêmicos, em especial do Diretório Hugo Simas, da Faculdade de Direito da UFPR. Esse grupo agia na tentativa de derrubar o presidente da UPE, segundo dados da DOPs de 28 de setembro de 1966. A mudança de rumo aconteceu a partir de setembro de 1967, com a vitória de Stenio Sales Jacob, identificado como comunista. Em 1967, a UPE, sob a direção de setores da esquerda estudantil, passou a ser combatida com maior força pelo poder policial. Tão logo esse grupo passou a controlar a UPE, observa-se uma ação conjunta da organização estudantil, a partir do documento intitulado "Comunicado ao povo", com data de 29 de setembro de 1967 e assinado pelo Diretório Central dos Estudantes da Universidade Federal do Paraná e pela União Paranaense de Estudantes. Além deles, aparecem como signatários os diretórios acadêmicos de cursos e de faculdades da UFPR: Diretório Acadêmico Guido Straub (Odontologia), Centro Acadêmico Hugo Simas (Direito), Diretório Acadêmico Nilo Cairo (Medicina), Diretório Acadêmico de Engenharia do Paraná (Engenharia Civil), Diretório Acadêmico Lycio Velozo (Agronomia), Diretório Acadêmico Bernardo Sayão (Engenharia Florestal), Diretório Acadêmico Victor do 
Amaral, Diretório Acadêmico Louis Pasteur (Farmácia), Diretório Acadêmico Rocha Pombo do Paraná (Faculdade de Filosofia, Ciências e Letras). Igualmente é signatário o Diretório Acadêmico Jackson de Figueiredo da Universidade Católica do Paraná.

No referido documento, a primeira mensagem informa: "nós, estudantes universitários paranaenses, vimos de público levantar o nosso veemente protesto face aos atos de vandalismo que estão sendo cometidos contra estudantes e intelectuais de todo país, em particular em nossa capital". ${ }^{40} \mathrm{Na}$ sequência, os estudantes descrevem:

Há dias vem o Exército Nacional efetuando prisões indiscriminadamente, arrancando pessoas de bem de nossa sociedade de seus lares e mantendo-os incomunicáveis, sem permitir-lhes sequer direito à defesa, num atentado à dignidade humana, tripudiando um direito inquestionável que é o de defesa. Missão ingrata essa assumida ultimamente pelo Exército Nacional que desdeu das suas altas funções para se entregar a uma atividade exclusivamente policial, cego, surdo e irreverente à condenação que o povo lhe faz. ${ }^{41}$

Mais adiante, o documento destaca que a ação dos militares buscava construir uma cultura generalizada de medo e pavor:

O pavor e o medo a que os militares querem impor à população traduz claramente os seus ardilosos objetivos e seus envilecidos propósitos de manter a situação atual que interessa tão somente a grupos escusos e alheios ao povo brasileiro. Por isso vemos nessas prisões o desenvolvimento de mais uma manobra do Exército para demonstrar ao povo que não tente concretizar o ideal de liberdade a qual, no entender deles, deve ser apenas um ideal de liberdade. ${ }^{42}$

Esse item procurou mostrar alguns aspectos do processo de 
organização estudantil do Paraná, em particular da UFPR que no final dos anos de 1950 e início da década de 1960 tinha atividades atreladas às pautas estudantis e a demandas gerais da organização social e política, como evidencia o desejo do Centro Acadêmico Hugo Simas em convidar Luiz Carlos Prestes para realizar palestra em Curitiba e as lutas dos estudantes que resultaram na participação na greve de 1962. Igualmente, nesta parte do artigo, buscou-se mostrar o aparelhamento da UPE no período do golpe militar e a tomada dessa organização estudantil pelos grupos alinhados aos setores considerados de esquerda a partir de 1967.

\section{Dos manifestos de 1968 ao desmonte da UPE e do DCE da UFPR}

Se antes de 1967 as mobilizações em Curitiba partiam das ações dos Diretórios Acadêmicos, depois houve uma comunhão de forças desses diretórios com a maior representação estudantil do Paraná, a saber, a UPE. Esse horizonte comum tem a ver com a tomada da UPE pelas lideranças ligadas à Juventude Católica Universitária e os diversos grupos dissidentes do PCB. Assim sendo, na capital do Paraná, as lutas se intensificaram. O ano de 1968 foi de intensa mobilização. No início do ano, o Diretório Central dos Estudantes (DCE) estava sob a direção de Jurandir Garçoni. A UPE estava sob a presidência de Stenio Sales Jacob. Essas entidades organizaram reuniões, distribuíram panfletos nas escolas, informando aos alunos sobre as medidas que seriam tomadas.

A pauta dos estudantes no que se refere à luta universitária acentuou o combate à política educacional do regime militar e a defesa de outro modelo de ensino superior, chamada pelos documentos da UNE de 
Universidade Crítica. Ao lado dessa pauta, somam-se as lutas contra a violência do regime autoritário. Essa organização já ocorria antes de 1968, mas em regra sob a organização de alguns centros acadêmicos. A partir da gestão de 1967, a UPE passou a coordenar essas manifestações de ruas. $\mathrm{Na}$ edição de junho de 1968, o jornal Política Operária, órgão do Partido Operário Comunista (POC), ${ }^{43}$ relata que no Paraná: “[...] 30, 31 de março e $1^{\circ}$ de abril: 3 dias de passeatas com 2 mil estudantes protestando contra o assassinato do Edson e contra a política educacional do governo". ${ }^{44}$ Conforme Figueiredo Filho, “o ano de 1968 se iniciou com a categoria mobilizada e disposta ao enfrentamento". ${ }^{45}$

O problema da anuidade estava na ordem do dia das lutas estudantis. Em 31 de outubro de 1967, o Conselho Universitário da UFPR havia estabelecido que a cobrança de anuidade deveria começar no ano seguinte, apenas para os novos alunos. A estratégia parecia bastante interessante, pois os estudantes já matriculados concluiriam seus cursos, sem pagamento. Essa medida estratégica não foi suficiente para conter os ânimos dos estudantes, pois em 1968, mais precisamente na:

Segunda quinzena de abril: inicia-se a luta contra as anuidades. A reitoria da Universidade Federal do Paraná havia fundado um curso noturno na Engenharia e fixaria a taxa de $\mathrm{NCr} \$ 1.3000 .00$ de anuidades. Isso era o primeiro passo do reitor Suplicy para implantar o ensino pago naquele estado. Os alunos da faculdade se organizaram em grupos de trabalho (GTs) e boicotaram as inscrições para o vestibular. Enquanto isso em todas as faculdades os estudantes já se organizavam para a luta contra os NCr\$ 100000 de anuidades, fixados só para os calouros, pelo astuto Suplicy. ${ }^{46}$

A ação estudantil em combate à cobrança de anuidades teve 
sequência, resultando em passeata, repressão e prisão.

Primeiros dias de maio Suplicy tenta novamente realizar o vestibular na Engenharia e 200 estudantes de várias escolas respondem com uma manifestação de rua. São reprimidos pela cavalaria e um terço dos manifestantes são presos. No mesmo dia mais 200 estudantes fazem uma manifestação em frente ao quartel da Polícia, com o intuito de libertar os colegas presos. São cercados por poderosa força policial, armada de bombas de gás, de efeito moral, metralhadoras e baionetas. Uma discussão com os estudantes impediu o massacre - mas os estudantes presos são - libertados na mesma noite. ${ }^{47}$

Esse episódio não impediu a continuidade da luta estudantil, pois “a radicalização continuou, com a assembleia e organização de mais GTs nas faculdades, unindo o movimento dos calouros com o dos vestibulandos de engenharia". ${ }^{48}$ Segundo Braga Portella, Christiane Szesz e Renato Leite, "[...] no dia 11 de maio, o Centro Politécnico foi ocupado pela polícia", 49 acontecendo confronto entre policiais e estudantes no domingo (dia 12). Nas assembleias de 13 de maio, com a participação de 6 mil estudantes, foi votada pela greve geral. Em sua defesa, o reitor da Universidade Flávio Suplicy afirmou que "[...] a cobrança é um preceito institucional. Impedir seu cumprimento é crime". ${ }^{50}$

A mobilização seguiu:

Paraná, 14 de maio: 100 estudantes, organizados em 10 grupos de 10 tomam a reitoria, cortando as comunicações para garantir a ocupação pela massa que veio posteriormente em numero de 2000 estudantes, armando barricadas nas esquinas, e exigindo a queda do reitor. No dia seguinte Suplicy já recua e atende as reivindicações dos calouros. Os estudantes fazem assembleias e insistem no não pagamento de anuidade em nenhum curso. Dias depois 
o Conselho Universitário aprova por unanimidade, com abstenção do reitor, a suspensão imediata da cobrança de anuidades (com devolução do que já tinha sido cobrado) e a criação de recursos especiais para o funcionamento gratuito dos cursos noturno de Engenharia e Direito (pretendiam fazer o mesmo nessa faculdade). ${ }^{51}$

Na Sessão do Conselho Universitário de 20 de maio de 1968, o reitor Flavio Suplicy fez oralmente relatório sobre o que ele chamou de distúrbios estudantis:

Desejo fazer ao Conselho relatório dos acontecimentos ultimamente verificados, para que o Conselho tenha pleno Conhecimento de tudo, e desejo relatar simplesmente fatos. Chegando aqui, de viagem ao Rio, no sábado [11 de maio], me entendi com o professor Leitner, que me participou ter pedido policiamento no centro politécnico, para impedir distúrbios, em vista de ter conhecimento de que estudantes iriam impedir os exames vestibulares para curso noturnos. Às 8 ou 7 horas, começaram os exames. Houve, então, tudo o que os senhores já sabem - luta entre estudantes e policiais [12 de maio]. Mas os exames, sob as garantias da polícia foram realizados. Infelizmente devemos lamentar uma vítima: seis soldados foram para o pronto socorro, um deles morreu quarta-feira [...]. ${ }^{52}$

O busto do Reitor Suplicy foi arrancado e arrastaram as imagens pelas ruas em um manifesto de grande proporção contra a universidade paga. Diante desse suposto descaso da polícia, Flávio Suplicy lamentou: “[...] hoje a polícia está aí - não pedi, porém”. ${ }^{33}$ Em seu entendimento, “[...] mesmo prevendo tal situação, tudo aconteceu, entretanto, sem interferência do reitor, mas fui responsabilizado por tudo". ${ }^{4} \mathrm{Na}$ avaliação de Flávio Suplicy, "[...] constatou-se também uma perfeita organização na operação da tomada do prédio da reitoria. Alguém guiou os estudantes. Houve 
técnica avançada, conforme constataram o SNI e a Polícia Federal". ${ }^{55}$

Em relação ao exposto do reitor, o vice-presidente do DCE, Raul Brasil, justificou as atitudes dos alunos: “[...] lutam por princípios e não contra alguém, e que o princípio defendido pelos estudantes é pela total gratuidade do ensino". ${ }^{56}$ Continuou: "[...] os estudantes sempre quiseram dialogar, e foi justamente por sentirem impedidos de fazê-lo, e como represálias pelas violências recebidas, é que resolveram demonstrar pela ação, em ato público, o seu ponto de vista, de repúdio a certas medidas os cursos pagos e as anuidades". ${ }^{57} \mathrm{Na}$ sequência, sob a relatoria do professor Brasil Pinheiro Machado, foi aprovada a seguinte proposição:

Fica revogada a resolução do Conselho Universitário, de 31 de outubro de 1967, que determinou a cobrança de anuidades; ficam também revogadas, as decisões do Conselho Universitário que instituíram o pagamento obrigatório de anuidades para os cursos noturnos, em regime especial. 58

A luta estudantil seguiu em frente, pois a gratuidade representava apenas uma parte de sua luta. De outra parte, as ações repressivas se mostravam cada vez mais atuantes. O jornal Política Operária procurava interpretar a ofensiva da UNE, quando denominou de "Uma perspectiva proletária para o movimento estudantil". Nessa matéria esse periódico sustentou:

A preparação do $\mathrm{XXX}^{\circ}$ Congresso Nacional dos Estudantes já se iniciou com a realização do Conselho da Bahia. Estão abertas as discussões em todas as bases estudantis. Um salto a frente nas perspectivas políticas e organizatórias da UNE: uma necessidade que se impõe, sob o signo das vitórias estudantis da França, e no Brasil, através do exemplo do Paraná. O congresso do ano passado foi um marco importante na evolução 
política do movimento estudantil brasileiro, quando definiu os primeiros princípios para uma política de massas correta, e definiu estratégia revolucionária para a UNE: "a integração da sua luta na luta dos trabalhadores pela transformação radical de nossa sociedade". Essas concepções influenciaram toda uma nova prática no movimento estudantil, radicalmente diferente daquela que se fazia até então. As lideranças procuraram levar as lutas reivindicatórias dos estudantes até as últimas consequências; a concepção de organização pela base se generalizou, na descoberta de novas formas de grupos de trabalho; o movimento estudantil teve uma participação mais ativa nas manifestações operárias. O próximo congresso deverá fazer avançar a atual carta programação e a ação da UNE. Para nós marxistas-leninistas, esse avanço significará levar às últimas consequências o objetivo da integração, ou seja, que esse congresso se defina claramente por uma perspectiva proletária. A UNE e o movimento estudantil ao se definirem pela causa histórica da classe operária, significa, não só a adesão física às manifestações operárias e a colaboração ativa com a vanguarda proletária, mas significa também, e este é o principal papel do movimento estudantil, uma luta intransigente contra o plano educacional da ditadura militar. $\mathrm{O}$ próprio avanço do movimento estudantil exige mais audácia de suas lideranças. Para os estudantes conscientes, uma luta audaz deve estar voltada efetivamente contra o regime. Duas frentes de luta devem ser bem definidas: uma dentro da universidade, visando retardar a aplicação do plano educacional do governo; outra junto à classe operária, apoiando suas lutas econômicas e assumindo suas lutas políticas. ${ }^{59}$

O evento, ocorrido em fevereiro na cidade de Salvador, previa a organização do $30^{\circ}$ Congresso da UNE, a realizar-se em outubro de 1968. $\mathrm{Na}$ avaliação de Figueiredo Filho:

As lideranças estudantis decidiram pela luta aberta, aproveitando-se do fato de estarem contando com o apoio de boa parte da sociedade e dos meios de 
comunicação. $\mathrm{O}$ mês de junho seria o da grande escalada do movimento, com greves e paralisações em diversas universidades por todo o país, culminando na passeata dos 100 mil, no Rio de Janeiro, no dia 26, com mais de seis horas de duração. ${ }^{60}$

Esse ambiente parece expressar a atmosfera ufanista manifestada pelo jornal Política Operária. A ala do Partido Operário Comunista que integrava o movimento estudantil procurava intensificar a articulação com os demais movimentos sociais. Nessa perspectiva, defende uma pauta específica de luta na universidade:

Gratuidade em todos os níveis de ensino, sem cobrança de nenhuma taxa; garantia de vagas no ensino primário e secundário para todos que desejam estudar; e ampliação crescente de vagas na universidade; autonomia de criação para o campo educacional (liberdade de expressão), inviolabilidade dos locais de ensino, independência de organização e participação política. Independência para a estipulação de currículos e participação igualitária de professores e alunos na direção do ensino; criação da Universidade Paralela, com seminários abertos para todos aqueles que desejam participar Estudantes ou trabalhadores. ${ }^{61}$

No âmbito das lutas universitárias, o grupo propôs o que chamava de reivindicações imediatas: "revogação do acordo MEC-USAID; reabertura do Calabouço; mais verbas para as universidades; liberdade de organização; fim da repressão ao movimento estudantil, das prisões e dos IMPs". ${ }^{62}$ Além disso, o grupo defendia as lutas gerais do movimento estudantil:

Participação ativa nas mobilizações e manifestações operárias; apoio às palavras de ordem da vanguarda operária: greve geral contra o arrocho e pela derrubada do regime; organização nas fábricas na forma de comitês; luta por sindicatos livres; luta anti-imperialista 
radical: manifestação em solidariedade FNL do Vietnã; solidariedade ativa aos estudantes europeus e a todos aqueles que travam uma luta radical contra $O$ imperialismo, apoio à OCLAE. ${ }^{63}$

As mobilizações estudantis continuaram após Maio de 1968. É fundamental destacar que essa organização paranaense deve ser compreendida, em geral, no interior do conjunto da mobilização social brasileira, mas, em particular, no âmbito das lutas dos estudantes em nível nacional, pois "o auge desses protestos e manifestações foi o ano de 1968 em que aconteceu a "Passeata dos Cem mil", a "Batalha da Rua Maria Antonia" e o XXX Congresso da UNE em Ibiúna (SP)". ${ }^{64}$

Em contrapartida a ação do poder policial se intensificava. No jornal Diário do Paraná, sob o título "Estudante que se manifestar será preso", a edição de 03 de setembro de 1968 dimensiona a organização da polícia para combater o movimento estudantil.

Todos os setores de segurança montaram um completo esquema, visando reprimir qualquer manifestação estudantil. Não permitirão qualquer comício relâmpago, pichações - tanto em ônibus, como em paredes e muros - nem qualquer mobilização da classe e quem for flagrado como subversivo vai para a "cana e ouvir um bom sermão". E só por enquanto os estudantes serão detidos. Mas depois as coisas vão se complicar se eles não deixarem de fazer barulho. "Não sabemos de nada, quanto aos futuros movimentos ou repressões, mas isto não pode acontecer". Esta é a palavra de ordem das autoridades policiais e a Secretaria de Segurança Pública tem mantido consecutivas reuniões. ${ }^{65}$

A fala (chamada de sermão) de um oficial da Polícia Militar a um aluno preso dá o tom aproximado do que pensavam as autoridades em 
relação ao movimento estudantil:

Essa estória de estudante discutir política e querer reformar o mundo vai acabar com eles. Só queremos ordem e paz. Passeata e pichação faz o pessoal, que não tem nada com a bronca sofrer, porque os ônibus saem de circulação e a cidade fica suja. Nada de passeata. Estudante tem que ficar quieto. ${ }^{66}$

De outra parte, o jornal Diário do Paraná (edição de 03 de setembro de 1968) informa que os universitários distribuíram panfleto que denunciava a repressão e a prisão de líderes estudantis. $\mathrm{O}$ manifesto "não foi considerado subversivo, mas não foi aconselhada a sua circulação entre os universitários". ${ }^{67}$ De acordo com o jornal O Estado do Paraná, “o manifesto começa assim: 'em todo o Brasil as manifestações estão proibidas, os estudantes estão sendo presos, espancados e baleados, as escolas invadidas. Também os operários, jornalistas, etc., são tratados dessa maneira, quando querem se manifestar"” ${ }^{68} \mathrm{Na}$ nota, continuavam: “os estudantes sofrem essa repressão porque lutam contra a política educacional do governo". ${ }^{69}$

Após o Congresso de Ibiúna, os estudantes paranaenses continuaram sua ofensiva. Em 07 de novembro de 1968 foi realizada eleição para o DCE da UFPR e UPE. Para o Diretório foi eleito Vitório Sorotiuk, oriundo do Centro Acadêmico Hugo Simas e para a UPE Berto Luiz Curvo, igualmente, oriundo do Hugo Simas. Das duas chapas que concorriam à UPE, o candidato a presidente, Berto Curvo, estava com prisão decretada. Já as duas chapas que concorriam ao DCE da UFPR, ambos os candidatos a presidente estavam com prisão decretada. A prisão dessas lideranças foi decretada no dia 21 de outubro de 1968, por meio da Auditoria de Guerra da Segunda Região Militar de São Paulo. A DOPs do Paraná recebeu, via 
telex, a informação do pedido de prisão preventiva dos estudantes Stenio Sales Jacob, Jurandir Rios Garçoni, Vitório Sorotiuk, Eloi Alfredo Pieta, Antonio João Manfio, Berto Luiz Curvo e Palmira Amâncio da Silva. ${ }^{70}$ Quarenta e cinco estudantes paranaenses foram presos no Congresso da UNE, na manhã de sábado do dia 13 de outubro de 1968. No dia 16 de outubro, quarenta e três chegaram a Curitiba, sendo todos liberados. O pedido de prisão preventiva dos estudantes foi expedido no dia 21 de outubro, quando já estavam todos soltos.

Mesmo com a ofensiva do poder policial, as lideranças do DCE e da UPE continuavam a organizar suas ações. A posse do presidente do DCE foi narrada em termos dramáticos, no dia 12 de novembro de 1968, pelo jornal O Estado do Paraná:

O estudante Vitório Sorotiuk, eleito na última quintafeira presidente do Diretório Central dos Estudantes da Universidade Federal do Paraná, tomou posse ontem perante as centenas de pessoas que compareceram à Reitoria para assistir à peça "O Santo Inquérito". Sua campanha para presidência do DCE foi efetuada clandestinamente na base de comícios relâmpagos realizados sob a proteção de esquemas de segurança armados pelos próprios estudantes. Ninguém acreditava que sua posse fosse efetuada publicamente. A encenação da peça teatral foi promovida com o objetivo prévio de dar um caráter público ao ato. Às 20 h30m, quando todos aguardavam o início do espetáculo, o presidente em exercício do DCE, Raul Brasil, anunciou que iria ser realizada a solenidade. Vitório Sorotiuk, que é aluno da Faculdade de Direito da UFP, surgiu no palco e, às pressas, assinou o termo de posse. Pronunciou breve discurso, afirmando seu propósito de imprimir ao DCE linha de trabalho idêntica à que vem sendo seguida no presente. ${ }^{71}$

Logo, na sequência, o reitor Flávio Suplicy pronunciou-se a respeito 
da eleição de Sorotiuk, em matéria publicada no jornal O Estado do Paraná, em 15 de novembro de 1968:

"Foi uma besteira imensa terem eleito esse rapaz", disse o Reitor Flávio S. de Lacerda, frisando que não aceita a posse de Vitório Sorotiuk no Diretório Central dos Estudantes. O reitor acrescentou que se Vitório comparecer a reitoria, terá de chamar a polícia para não ser considerado cúmplice. "Se vier, será preso. Mas ele não vem mesmo, tenho certeza". Mais adiante, comentou: "o movimento estudantil, como está sendo organizado, é uma traição à pátria. Os estudantes, todos eles, estão recebendo instruções de Cuba. Um sujeito que recebe instruções de um país estrangeiro para subverter a ordem em seu país é um traidor. Até hoje eles não disseram o que querem. Recusaram a comparecer ao Grupo de Trabalho da Reforma e, veja bem, todos os estudantes foram convidados a participar, e todos se negaram". ${ }^{72}$

Em 12 de dezembro de 1968, Vitório Sorotiuk e mais seis estudantes paranaenses obtiveram habeas corpus, no Supremo Tribunal Federal. Essa decisão foi noticiada pelo jornal Diário do Paraná, no dia 13 de dezembro de 1968.

Sete estudantes do Paraná, juntamente com outros 71 em todo país que estavam com prisão preventiva decretada pela Auditoria da $2^{a}$ Região Militar, foram beneficiados com "habeas corpus" pelo Supremo Tribunal Federal, sendo que 46 receberam soltura imediata. Os estudantes foram presos em Ibiúna, quando participavam do $30^{\circ}$ Congresso da União Nacional de Estudantes. O STF não entrou no mérito dos pedidos limitando-se a mandar colocar os estudantes em liberdade, por decurso de prazo de prisão. No Paraná, todos os estudantes já estavam circulando livremente pelas ruas. ${ }^{73}$

Tão logo teve sua prisão preventiva suspensa, "Vitório Sorotiuk, presidente eleito do DCE, esteve ontem mesmo com o vice-presidente, 
Manoel Fogaça, acertando os detalhes administrativos, no que diz respeito a confecções de relatórios, orçamentos e esquema de trabalho". ${ }^{74}$ Entretanto, um dia após a expedição do habeas corpus, foi baixado o Ato Institucional $5^{75}$ que impedia esse tipo de concessão a crime contra segurança nacional. A DOPs Paraná recebeu despacho em caráter urgentíssimo, via telex, do Departamento de Polícia Federal de São Paulo, com data de 17 de dezembro, informando que:

Os indiciados STENIO SALES JACOB, JURANDIR RIOS GARÇONI, VITÓRIO SOROTIUK, PALMIRA AMÂNCIO DA SILVA, ELOI ALFREDO PIETA, ANTONIO JOÃO MANFIO e BERTO LUIZ CURVO, todos estudantes nesse estado se ainda não foram postos em liberdade deverão continuar presos. ${ }^{76}$

Nesse mesmo mês, o movimento estudantil paranaense sofreu pesada ofensiva com a entrada das tropas policiais no congresso, realizado no Boqueirão, bairro da região sul de Curitiba. No dia 17 de dezembro, conforme o jornal Diário do Paraná, foram presos quarenta e dois estudantes, sendo 5 moças e 37 rapazes. Entre esse grupo estavam as principais lideranças da UPE (Berto Curvo) e do DCE (Vitório Sorotiuk). O impresso relatou que "a reunião dos estudantes foi iniciada às 9 horas da manhã para debater a aprovação da 'carta política' e outros temas ligados à extinta UNE, todos eles contrários à Lei de Segurança Nacional". ${ }^{77}$ Porém, foram surpreendidos pelas autoridades policiais, pois “às $11 \mathrm{~h} 20 \mathrm{~m}$, a reunião clandestina estava encerrada com seus participantes presos e logo após caminhando em coluna por um, com as mãos para o alto, subiam nas viaturas que os conduziria para o Regimento de Cavalaria, no Tarumã e posteriormente à Prisão Provisória". ${ }^{78}$ Desses quarenta e dois estudantes, 
quinze foram autuados e permaneceram presos. Os demais foram fichados e liberados. Entre os quinze, estavam Berto Curvo e Vitório Sorotiuk, conforme matéria da Gazeta do Povo de 19 de dezembro de $1968 .^{79}$ Não bastasse a prisão preventiva, o Diário do Paraná, em 19 de junho de 1969, noticiou a condenação de estudantes paranaenses, com penas de seis meses a dois anos de prisão. "Entre os condenados estão os estudantes João Antonio Manfio, José Vieira Laercio, Sebastião Carlos e Cruz, Vitório Sorotiuk (eleito presidente do DCE), [sic] Steler, Lenine Bueno Monteiro, Berto Luiz Curvo, Stenio Sales Jacob e Palmira Amâncio Silva". 80

Antes disso, no início de 1969 houve golpe implacável contra os estudantes paranaenses, quando o DCE e a UPE foram extintos. Conforme notícia do jornal O Estado do Paraná, de 24 de agosto de 1968, o processo referente à extinção da UPE estava na Justiça Federal. ${ }^{81}$ No entanto, a determinação final ocorreu no dia 23 de janeiro de 1969, conforme relato de vários jornais da capital do Paraná. O Estado do Paraná publicou duas matérias: uma com o título "Patrimônio da UPE agora é da Reitoria"; outra, intitulada "Juiz mandou fechar UPE". A Tribuna do Paraná lançou: "Consumada ontem a extinção da UPE".

Em audiência realizada ontem na $2^{a}$ Vara da Justiça Federal, foi lida e publicada a sentença do Juiz Milton Luiz Pereira extinguindo a União Paranaense dos Estudantes. Na sentença, o juiz federal determina que os bens móveis e imóveis da UPE se incorporem ao patrimônio da Universidade Federal do Paraná, "ficando, por destinação específica quanto ao seu uso e gozo, garantida sua utilização pelo Diretório Central dos Estudantes". 82

Na Tribuna do Paraná consta a fundamentação legal da extinção da 
UPE:

O Decreto extinguindo a União Paranaense dos Estudantes foi assinado pelo Presidente Costa e Silva no dia 28 de fevereiro de 1967, depois das anteriores legislações que disciplinavam a existência de entidades estudantis: a lei 4.464, chamada "Lei Suplicy", e o "Decreto Aragão", que a substituiu. A primeira, criando outra entidade de âmbito estadual, Diretório Estadual dos Estudantes, e a segunda proibindo a existência de entidades estudantis nesse âmbito, o que tornou a UPE, como órgão de representação dos universitários, ilegal. 83

Extinta a UPE, o combate passou a ser contra o DCE da UFPR. Na sessão do Conselho Universitário de 26 de fevereiro de 1969, Suplicy de Lacerda tratou da Portaria 5.373, de 25 de fevereiro de 1969, por meio da qual a reitoria determinava a ocupação provisória da sede do DCE pelo Departamento de Educação e Cultura da UFPR. ${ }^{84} \mathrm{O}$ presidente do Conselho informou que a Portaria foi estabelecida a partir da anulação do pleito eleitoral, emitida pelo Conselho Federal de Educação (CFE). A motivação para a anulação do processo eleitoral pautava-se no Decreto 228/67. ${ }^{85} \mathrm{Na}$ oportunidade, o Conselho Universitário acompanhou a posição do CFE e anulou a eleição de 1968 e autorizou a reitoria a publicar convocação de novas eleições. Ao cotejar as atas do Conselho Universitário, não observamos que a reitoria tenha realizada essa convocação. No entanto, estava em curso a reorganização do estatuto da UFPR em consonância com a Lei. 5540/68. Em discussão na reunião de 02 de novembro de 1969, o representante discente propôs que se incluísse no estatuto a permissão de organização de diretórios acadêmicos. ${ }^{86} \mathrm{O}$ conselheiro professor Alceu Ribeiro de Macedo registrou que não haveria necessidade de constar no estatuto, pois a lei 5.540, no capítulo III, já normatizava a organização 
estudantil. $^{87}$

A ação da reitoria foi de ofensiva contra o DCE. Em matéria publicada, no dia 01 de março de 1969, no jornal Diário do Paraná, consta a posição da reitoria da UFPR.

A Reitoria da Universidade Federal do Paraná distribuiu nota, informando que elementos do Diretório Central de Estudantes, depredaram na noite de quinta-feira, a sede da entidade, em protesto contra a decisão do Conselho Federal de Educação que não reconheceu a diretoria eleita como legalmente constituída. Ao tomar conhecimento, o reitor Flávio Suplicy de Lacerda disse que um "acontecimento dessa natureza é fundamentalmente criminoso" e, por isto, a sede do DCE será ocupada por órgãos da reitoria. Esclarece a nota que os "elementos do DCE depredaram o patrimônio da União, estando assim, sujeitos às sanções previstas em lei". Segundo o reitor Flávio Suplicy de Lacerda, que ontem mostrava-se muito chocado com a depredação criminosa, o Diretório Central dos Estudantes poderá ser extinto, face a nova legislação. ${ }^{8} 8$

$\mathrm{Na}$ ata da Sessão do Conselho de 18 de março de 1969, o Conselho baixou a Resolução 1/69 para deliberar que:

1) As dependências do Centro Social da Universidade, que estavam servindo de sede para o DCE, passarão a ser ocupadas pelo Centro de Bibliografia e Documentação do Departamento de Educação e Cultura da Reitoria, atualmente no Centro Politécnico; 2) autorizar a Reitoria a arrendar o Restaurante, que estava sob a administração do DCE, a um dos Diretórios Acadêmicos que atualmente exploram restaurantes estudantis; 3) Quanto ao DCE, se continuar a existir, deverá se instalar em outro local, a ser escolhido e pago pelo próprio DCE. ${ }^{89}$

No interior da UFPR, com as lutas de abril e maio de 1968 houve a 
garantia de não cobrança de anuidades. Essa pauta e tantas outras demarcam os posicionamentos e as ações do Diretório Central dos Estudantes da UFPR, dos diretórios ou centros acadêmicos dos diversos cursos, da União Paranaense dos Estudantes e de outros diretórios e centros de demais instituições universitárias da capital e do interior do Paraná. Entretanto, a batalha que resultou no cancelamento da cobrança da anuidade na UFPR não implicou o arrefecimento do combate aos estudantes. Duas frentes implacáveis das autoridades garantiram a desmobilização da ação dos estudantes. A UPE foi extinta em janeiro de 1969, sendo reorganizada em 1980. O DCE foi fechado no início de 1969, sendo reaberto apenas no dia 01 de maio de 1976. Apesar disso, o maio de 1968 no Paraná parece marcar a geração dos estudantes que lutavam por mudanças concretas, como a garantia da gratuidade, a denúncia das arbitrariedades da ditadura militar e a utopia por uma nova organização societária. Sem a UPE e sem o DCE, a organização estudantil da UPFR estava nos diretórios ou centros acadêmicos dos cursos, mas sob forte controle e vigilância das forças militares e dos agentes da própria UFPR. Essa ação que resultou nas medidas contra o DCE estava em consonância com o que disse o Reitor Suplicy de Lacerda ao Diário do Paraná, em 21 de fevereiro de 1969: “a resolução tomada pelo Conselho [Federal de Educação - anulação da eleição do DCE] torna dispensável a existência de Diretórios Acadêmicos e onde houver, deverão ter como finalidade a cooperação entre administradores, professores e alunos no trabalho universitário". ${ }^{90}$ Portanto, a partir de então, sob a guarda do Ato Institucional 5, a ofensiva contra os estudantis foi implacável, pois as principais lideranças paranaenses estavam presas, as mobilizações foram 
fortemente perseguidas e a organização estudantil tendia a ser transformada em instância de cooperação ao trabalho universitário.

\section{Conclusões}

Este artigo tematizou o Maio de 68 na UFPR, privilegiando uma abordagem sobre a organização estudantil. Esse acontecimento foi tomado como abertura de possíveis e resultado de acontecimentos antecedentes. Assim sendo, a narrativa deste texto trouxe esses dois aspectos para problematizá-lo, pois “[...] uma crise como a de maio de 1968 - e sem dúvida toda crise - introduz uma ruptura visível em relação ao que a precedeu, ainda que só se possa compreendê-la ressituando-a na série dos acontecimentos antecedentes". ${ }^{91}$ Deleuze e Guattari enfatizam a ideia de ruptura, uma vez que "[...] o próprio acontecimento, por mais antigo que seja, não se deixa ultrapassar: ele é abertura de possível. Ele passa para dentro dos indivíduos, tanto quanto para dentro da espessura de uma sociedade". ${ }^{92}$

Maio de 68 não pode ser reduzido a uma cadeia causal. Não pode ser compreendido como decorrência dos acontecimentos anteriores. Porém, na sua compreensão, também, está contida a ideia de acontecimentos antecedentes, como alertava Bourdieu. Nesse aspecto, a narrativa deste texto destacou que a organização estudantil paranaense estava associada a esse movimento mundial, perpassado por diferentes atores sociais. As lutas se constituíram de pautas particulares, como a gratuidade do ensino superior e a reforma universitária. No entanto, existiam elementos que aproximavam os diversos grupos. Um elemento de 
grande reverberação tratava-se da unificação de lutas em torno da utopia de mudança social, em particular ao buscar associar as organizações a uma nova ordem social. As colorações ganhavam particularidades em cada país e continente. Nos países como Brasil, o ideário anti-imperialista ganhava adesão. Igualmente, as reformas de base que estavam em marcha, no início de 1960. A guinada autoritária no Brasil representou a supressão desse horizonte de expectativa que embalava as lutas da UNE, a partir de 1962. O regime militar se apresentou, imediatamente, implacável contra a organização estudantil, passando a legislar e conformar outras agremiações representativas. De outro lado, os estudantes da UNE, mesmo na clandestinidade, continuaram a organização e a estabelecer estratégias de mobilização.

No Paraná, a organização estudantil estava representada na UPE. Porém, essa entidade tinha pouca força de mobilização até 1967. Logo após o início da ditadura militar, essa instituição deu apoio irrestrito ao governo. Em contrapartida, alguns centros acadêmicos da UPFR, em especial o Hugo Simas, no final dos anos de 1950, já associavam as lutas estudantis a outros movimentos da esfera política e social. Assim continuou a agir essa organização do curso de Direito da universidade paranaense. Esse grupo assumiu o DCE da UFPR. Em 1967, assumiu, também, a UPE, transformando-a em um dos principais espaços de luta contra as políticas educacionais do Ministério da Educação, em contraposição às ações da reitoria da UFPR e ao regime autoritário da ditadura. Esse processo foi capitaneado pelo Centro Acadêmico Hugo Simas, resultando na tomada do DCE e da UPE, assim como nas marchas que decretaram a ocupação do prédio da reitoria e a supressão do ensino pago na UPFR. 
A compreensão de Maio de 1968, também está dada na acepção de que "[...] é da ordem de um acontecimento puro, livre de qualquer causalidade normal ou normativa. A sua história é uma 'sucessão de instabilidades e de flutuações amplificadas". ${ }^{93}$ Essa observação reitera outra preocupação deste artigo, qual seja, dar visibilidade ao Maio de 68 na UFPR como um acontecimento que produziu rupturas ao estado de coisas que estava dado até aquele momento. As ações dos jovens estudantes no Hugo Simas, no DCE e na UPE, as atividades de mobilização, a estratégia para posse de Vitório Sorotiuk em meio a centenas de pessoas que esperavam o início da peça teatral, as marchas pelas ruas, os confrontos com a polícia no Centro Politécnico, a ocupação da reitoria, a derrubada e o ato de serrar o nariz do busto do reitor Suplicy, as reuniões, os congressos, as fugas, as declarações à imprensa sem revelar as ações de clandestinidade, as prisões, enfim, tantas outras, evidenciam o inesperado, o dramático, a utopia, o sonho. Nesse sentido, "o que conta é que foi um fenômeno de vidência, como se uma sociedade visse, de repente, o que ela tinha de intolerável, e visse também a possibilidade de outra coisa". ${ }^{94}$ Em outras palavras, aquelas ações expressavam " [...] um fenômeno coletivo na forma de: 'um pouco de possível, senão eu sufoco...' O possível não preexiste, é criado pelo acontecimento. É uma questão de vida. O acontecimento cria uma nova existência, produz uma nova subjetividade [...]".95

As forças institucionalizadas, em particular os aparatos estatais, assim como outros grupos sociais, demonstraram grande dificuldade para compreender as ações dos estudantes. A julgar pelas inúmeras declarações e ações de autoridades relatadas neste texto, é possível sustentar algo semelhante ao que disseram Deleuze e Guattari sobre a reação da sociedade 
francesa: "ela não soube propor nada às pessoas: nem no domínio da escola, nem no do trabalho. Tudo o que era novo foi marginalizado ou caricaturizado". 96 No interior da UFPR, as demandas imediatas dos estudantes foram atendidas, em especial a supressão da cobrança de anuidades. Porém, os meses seguintes materializaram a ação implacável do poder legal das autoridades civis e militares contra as possibilidades históricas abertas pelo Maio de 68. As censuras, as prisões, as condenações das principais lideranças estudantis e o fechamento do DCE e da UPE expressam o contundente mecanismo repressor afiançado pelo Ato Institucional 5.

\section{Notas}

*Pós-Doutor em História. Professor no Programa de Pós-Graduação em Educação da Universidade Estadual de Ponta Grossa, Paraná. Email: ndoutorado@yahoo.com.br. Orcid: https://orcid.org/0000-0003-1850-316X).

**Doutor em Educação. Servidor Público na Universidade Estadual de Ponta Grossa, Paraná. E-mail: eliezer.felix@hotmail.com. Orcid: http://orcid.org/0000-0002-7354-387X

${ }^{1}$ Neste texto não é possível explicitar a produção existente sobre Maio de 1968. Em alguns momentos fazemos indicação direta ao debate internacional e brasileiro. Porém, na narrativa deste artigo está implícita essa relação, pois não é possível pensar o movimento estudantil de 1968 na UFPR sem estar articulado explícita ou implicitamente com o movimento estudantil brasileiro e do exterior, assim como com os demais movimentos sociais daquele momento. Assim sendo, destacamos a pesquisa intitulada Movimento estudantil 68: imagens da paixão, escrita por Rafael Rosa Hagemayer (1997). Na introdução dessa dissertação, o autor faz um balanço das produções sobre os movimentos sociais, assim como do movimento estudantil, no contexto da ditadura civil-militar brasileira. Além disso, ressaltamos que a Revista Mediações publicou um dossiê, dividido em duas partes (2007/2008), tratando dos 40 anos de Maio de 1968, cujos artigos cobrem desde aspectos do contexto europeu até discussões específicas do Brasil. Por fim, na tese de Mateus da Fonseca Capssa Lima (2017), intitulada Direita estudantil universitária no Rio Grande do Sul: entre a democracia e a ditadura (1961-1968), em específico na introdução, há uma síntese das pesquisas que tratam do movimento estudantil no Brasil. Essa opção tem uma razão de ser: 
dar visibilidade à originalidade deste artigo, pois as discussões gerais estão à disposição do leitor, como as indicadas nas linhas anteriores.

2 BOURDIEU, P. Homo academicus. Florianópolis: UFSC, 2013. pp. 208-209. 3 ibid, p. 209.

${ }^{4}$ DOSSE, F. Renascimento do acontecimento: um desafio para o historiador - entre Esfinge e Fênix. São Paulo: UNESP, 2013. p. 6.

5 ibid, p. 128.

${ }^{6}$ THIOLLENT, M. Maio de 1968 em Paris: testemunho de um estudante. Tempo Social, São Paulo, v. 10, 1998. p. 65.

7 idem.

8 idem.

9 ANTUNES, R; RIDENTI, M. Operários e estudantes contra a Ditadura: 1968 no Brasil. Mediações, v. 12, 2007. p. 79.

${ }^{10}$ RIDENTI, M. 1968: rebeliões e utopias. In: REIS FILHO, D. A. et al. (Org.). O século XX: o tempo das dúvidas - do declínio das utopias às globalizações. Rio de Janeiro: Civilização Brasileira, 2002. p. 149.

${ }^{11}$ ANTUNES; RIDENTI, op. cit. p. 79.

12 ibid, p. 80.

13 HAGEMAYER, R. R. 1968: a derrubada do ensino pago no Paraná. In: MARTINS FILHO, J. R. (Org.). 1968 faz trinta anos. Campinas, SP: Mercado de Letras, 1998. pp. 95-128.

${ }_{14}$ PORTELA, J. R. B. et al. Contextos e traumas do maio de 1968 na UFPR. In: LOPES LEITE, R.; OLIVEIRA, R. C. (Org.). Reflexões UFPR 100 anos (19122012). Curitiba: UFPR, 2012. pp. 103-115.

15 SCHMITT, S. L.; FIUZA, A. F. A DOPS e a vigilância política do movimento estudantil paranaense durante a ditadura civil-militar. Revista Histedbr, n. 45, 2012. pp. 101-114.

16 ZAPARTE, A. A DOPS e a repressão ao movimento estudantil em Curitiba - Paraná (1964-1969). 2011. Mestrado, PPGH-UNIOESTE, Marechal Cândido Rondon, PR, 2011.

${ }^{17}$ COSTA, A. A repressão no Estado do Paraná durante o Regime Militar: o movimento estudantil e a operação Marumbi. Maringá: Núcleo Regional de Educação, 2008.

${ }^{18}$ MANSAN, J. V. A educação superior sob vigilância: o caso da DOPS/PR (19641988). Revista HISTEDBR, Campinas, 2013, v. 13, pp. 14-26.

${ }^{19}$ SZWAKO, J. E. L. Da Faculdade à Academia: mecanismos de reprodução e estruturação burocrática do Setor de Ciências Humanas, Letras e Artes da UFPR (1974-1986). 2005. Mestrado, PGSOCIO-UFPR, Curitiba, 2005.

${ }^{20}$ BRASIL NUNCA MAIS, Pasta 279.19193.

${ }^{21}$ COSTA, C. S. B. C. Movimento estudantil contemporâneo: uma análise compreensiva das suas formas de atuação. Doutorado, PPGS-UFPE, Recife, Brasil, 2004. p. 76. 
22 COSTA, op. cit., p. 77.

23 A União Estadual dos Estudantes do Paraná, denominada de União Paranaense dos Estudantes, foi criada em 1939. Ela foi extinta em 1969.

24 ZAPARTE, op. cit., p. 79.

${ }^{25}$ LIMA, M. F. C. Direita estudantil universitária no Rio Grande do Sul: entre a democracia e a ditadura (1961-1968). Doutorado, PPGH-UNISINOS, São Leopoldo, RS, 2017. p. 139.

26 CUNHA, L. A. A universidade crítica: o ensino superior na República Populista. Rio de Janeiro: Francisco Alves, 1989. p. 217

27 ibid, p. 242.

28 ibid, p. 243.

29 ibid, p. 149.

30 idem.

31 ZAPARTE, op. cit., p. 81.

32 ZAPARTE, op. cit., p. 84.

33 SANTOS, J. S. A repressão ao movimento estudantil na ditadura militar. Aurora, n. 5, 2009. p. 105.

34 BRITO, A. M. F. O golpe de 1964, o movimento estudantil na UFBA e a resistência à ditadura militar (1964-1968). Doutorado, PPGH-UFBA, Salvador, 2008. p. 123.

35 idem.

36 DOPS - PR, BR PRAPPR.PB004.PT 2325.263.

${ }^{37}$ DOPS - PR, BR PRAPPR.PB004.PT 2325.263.

38 ZAPARTE, op. cit., p. 96.

39 BR PRAPPR.PB004.PT 2325.263.

40 DOPS - PR, BR PRAPPR.PB004.PT 512.527.

${ }^{41}$ DOPS - PR, BR PRAPPR.PB004.PT 512.527.

${ }^{42}$ DOPS - PR, BR PRAPPR.PB004.PT 512.527.

43 O POC foi fundado em abril de 1968. Permaneceu até 1971. Foi constituído pelos antigos grupos dissidentes do PCB. Mais informações consultar FIGUEIREDO FILHO, C. R. Partido Operário Comunista (POC): história e memória de uma organização marxista-leninista (1968-1971). Doutorado, PPGHUSP, São Paulo, 2016.

44 JORNAL POLÍTICA OPERÁRIA, junho 1968, p. 6. In: Arquivo Brasil Nunca Mais, Pasta 066.988-999.

45 FIGUEIREDO FILHO, C. R. Partido Operário Comunista (POC): história e memória de uma organização marxista-leninista (1968-1971). Doutorado, PPGH-USP, São Paulo, 2016. p. 165.

46JORNAL POLÍTICA OPERÁRIA, op. cit., p. 6.

47 idem.

48 idem.

49 PORTELA, et al, op. cit., p. 108. 
50 ibid, p. 109.

51 JORNAL POLÍTICA OPERÁRIA, op. cit., p. 6.

52 UNIVERSIDADE FEDERAL DO PARANÁ. Conselho Universitário. Ata da Sessão de 20 de maio de 1968.

53 idem.

54 idem.

55 idem.

56 idem.

57 idem.

58 idem.

59 JORNAL POLÍTICA OPERÁRIA, op. cit., p. 6-7.

${ }^{60}$ FIGUEIREDO FILHO, op. cit., p. 167.

${ }^{61}$ JORNAL POLÍTICA OPERÁRIA, op. cit., p. 7.

62 idem.

63 idem.

${ }^{64}$ SANTOS, op. cit., p. 101.

65 DIÁRIO DO PARANÁ, 03 de setembro de 1968, s. p. In: Arquivo DOPS PR, BR PRAPPR.PB004.PT 742.84.

66 DIÁRIO DO PARANÁ, op. cit., s. p.

${ }^{67}$ idem.

68 idem.

69 idem.

70 DOPS - PR, BR PRAPPR.PB004.PT2312.260.

71 O ESTADO DO PARANÁ, 12 de novembro de 1968, s. p. In: Arquivo: DOPS - PR, BR PRAPPR.PB004.PT 742.84.

72 O ESTADO DO PARANÁ, 15 de novembro de 1968, s. p. In: Arquivo: DOPS

- PR, BR PRAPPR.PB004.PT 742.84.

73 DIÁRIO DO PARANÁ, 13 de dezembro de 1968, s. p. In: Arquivo: DOPS PR, BR PRAPPR.PB004.PT 742.84.

74 idem.

75 BRASIL. Ato Institucional no 5, de 13 de dezembro de 1968.

76 DOPS - PR, BR PRAPPR.PB004.PT2312.260.

77 DIÁRIO DO PARANÁ, 17 de dezembro de 1968, s. p. In: Arquivo: DOPS PR, BR PRAPPR.PB004.PT2312.260.

78 idem.

${ }^{79}$ GAZETA DO POVO, 19 de dezembro de 1968, s. p. In: Arquivo: DOPS - PR, BR PRAPPR.PB004.PT2327.264.

80 DIÁRIO DO PARANÁ, 19 de junho de 1969, s. p. In: Arquivo: DOPS - PR, BR PRAPPR.PB004.PT742.84.

81 O ESTADO DO PARANÁ, 24 de agosto de 1968, s. p. In: Arquivo: DOPS PR, BR PRAPPR.PB004.PT2327.264.

82 TRIBUNA DO PARANÁ, 24 de janeiro de 1969, s. p. In: Arquivo: DOPS - 
PR, BR PRAPPR.PB004.PT2327.264.

83 idem.

${ }^{84}$ UNIVERSIDADE FEDERAL DO PARANÁ. Conselho Universitário. Ata da Sessão de 26 de fevereiro de 1969.

85 BRASIL. Decreto-lei $\mathrm{n}^{\circ}$ 228, de 28 de fevereiro de 1967. Este Decreto normatizou a organização estudantil, estabelecendo o Diretório Central dos Estudantes e os Diretórios Acadêmicos. Na norma proíbe-se qualquer atividade de caráter político e prescreve-se que as entidades devem ter caráter cultural e assistencial. Além disso, prevê a suspensão e supressão dessas entidades, em caso de descumprimento das determinações. Com base nessa normatização a UFPR extinguiu o DCE.

${ }^{86}$ UNIVERSIDADE FEDERAL DO PARANÁ. Conselho Universitário. Ata da Sessão de 02 de novembro de 1969.

87 O Estatuto da UFPR foi aprovado pelo Conselho Federal de Educação, na sessão de 12 de março de 1970.

${ }^{88}$ DIÁRIO DO PARANÁ, 01 de março de 1969, s. p. In: Arquivo: DOPS - PR, BR PRAPPR.PB004.PT742.84.

${ }^{99}$ UNIVERSIDADE FEDERAL DO PARANÁ. Conselho Universitário. Ata da Sessão de 18 de março de 1969.

${ }^{90}$ DIÁRIO DO PARANÁ, 21 de fevereiro de 1969, s. p. In: Arquivo: DOPS PR, BR PRAPPR.PB004.PT2327.264.

${ }^{91}$ BOURDIEU, op. cit., p. 209.

92 DELEUZE G.; GUATTARI, F. Maio de 68 não ocorreu. Revista Trágica: estudos de filosofia da imanência, 2015, v. 8, n. 1. p. 119.

93 idem.

94 idem.

95 idem.

96 ibid, p. 120. 